
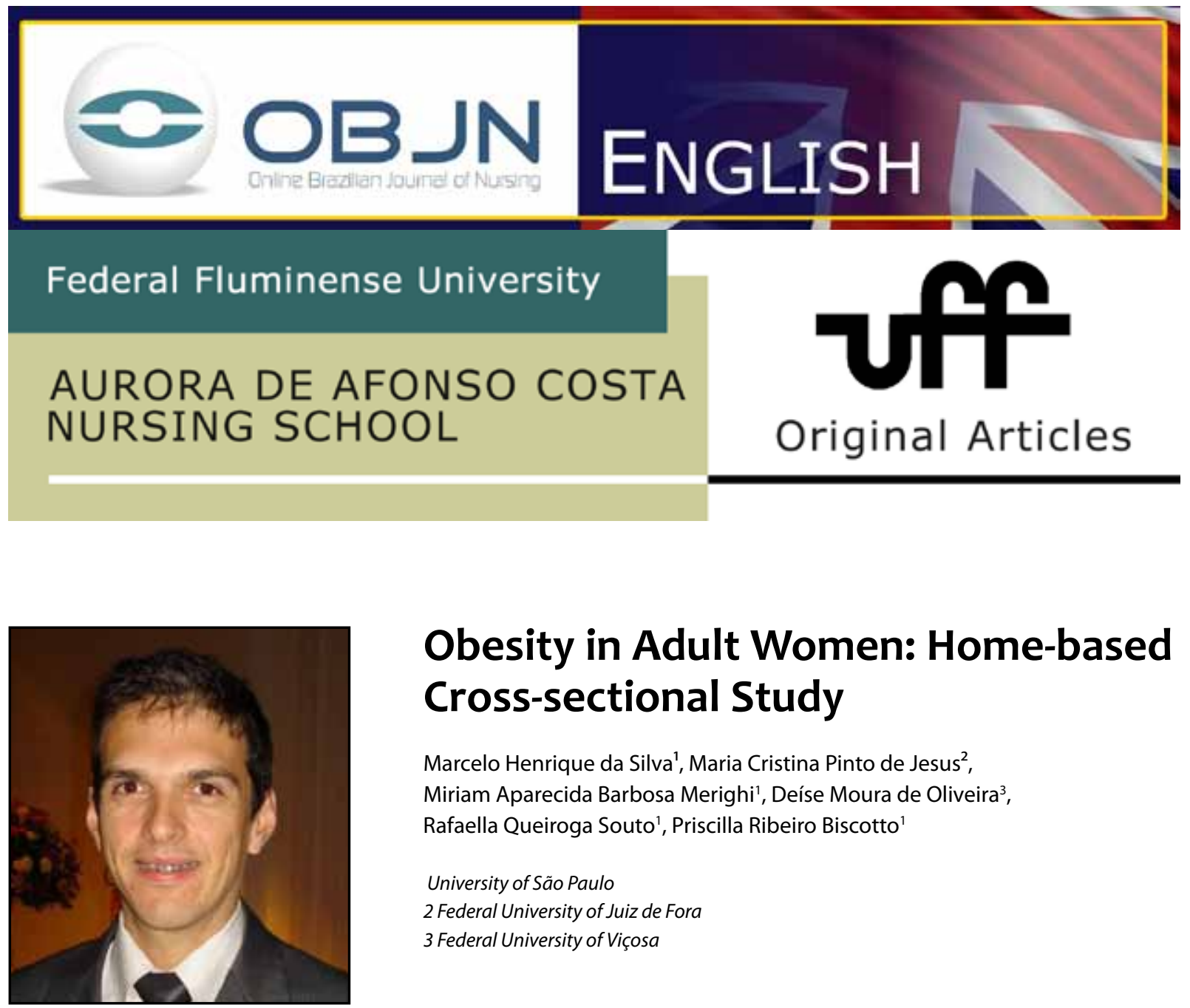

\title{
Obesity in Adult Women: Home-based Cross-sectional Study
}

\author{
Marcelo Henrique da Silva', Maria Cristina Pinto de Jesus², \\ Miriam Aparecida Barbosa Merighi' ${ }^{1}$ Deíse Moura de Oliveira ${ }^{3}$, \\ Rafaella Queiroga Souto', Priscilla Ribeiro Biscotto' \\ University of São Paulo \\ 2 Federal University of Juiz de Fora \\ 3 Federal University of Viçosa
}

\section{ABSTRACT}

Aim: To estimate the prevalence of obesity and associated factors in adult women. Method: This is a crosssectional study of 240 women enrolled in primary care in a city in the state of Minas Gerais. Data collection took place between April and July 2012. Results: The prevalence of obesity was 37.08 percent $(n=89)$. The following variables are associated with Body Mass Index (BMI): age ( $p=0.000, O R=3.35, C l=1.9$ to 5.8), contraceptive use $(p=0.00)$, disease associated with obesity $(p=0.00)$ and use of sugar to sweeten drinks $(p=0.00, O R=3.8, C l=11.5)$. Discussion: The prevalence of obesity was higher than that found at national and global levels. The factors associated are congruent with those found in the literature. Conclusion:When planning and executing actions aimed at controlling female obesity, managers and health professionals should consider this evidence.

Descriptors: Obesity; Nursing; Epidemiology. 


\section{INTRODUCTION}

The global epidemic of obesity is apparent in the contemporary world, and reflects social, economic and cultural problems in both developing and developed countries ${ }^{(1)}$. Considered a complex disease, obesity has serious social and psychological repercussions that can cause great damage to life ${ }^{(2)}$. Approximately 12 percent of the population is considered obese, totaling more than 300 million adults around the world. Furthermore, obesity is associated with the mortality of 2.8 million people per year ${ }^{(3)}$.

In Brazil, nutritional indicators show an abrupt decline in malnutrition and at the same time, an increase in the prevalence of the overweight and obese. The number of individuals who are overweight increased from 42.7 percent in 2006 to 48.5 percent in 2011 . In the same period, the proportion of obese individuals increased from 11.4 percent to 15.8 percent. For women, those overweight were estimated at 44.7 percent and those obese, 16 percent, thus highlighting the presence of this condition in the female population ${ }^{(4)}$.

Worldwide, research findings corroborate that obesity affects more women than men, which presents a serious public health problem in the 21 st century ${ }^{(5)}$. Given the magnitude of the problem, it is evident that the Unified Health System (UHS), needs to focus on actions and goals related to public health care. Health actions should be based on evidence, and actions of a preventive and curative nature, aimed at combating obesity, should occur in a concrete and precise manner after meeting with the identified women ${ }^{(4)}$.

Taking into account the extent of this problem and the lack of records in DATASUS ${ }^{(6)}$ that express the prevalence of obesity in the female population of the municipality of this research, the objective is to estimate the prevalence of obesity and associated factors in adult women seeking care in primary health care (PHC). This may highlight the details of the problem, provide support for the creation and promotion of public policies, and indicate the possible health actions required for this group.

\section{METHOD}

This is a home-based cross-sectional study conducted in a city in the state of Minas Gerais, with an estimated population of $516,247^{(7)}$. The number of people enrolled on the Information System of Primary Care (ISPC) in 2012 was 261,370, with 49.62 percent covered by the Family Health Strategy (FHS) (8). The population of this study is the 94,156 adult women aged between 20 and 59 years.

According to a survey conducted in 2008 by the Brazilian Institute of Geography and Statistics (IBGE), obesity is prevalent in 16.9 percent of the female population of Brazil, and for the sample size calculation, we used the formula of cross-sectional studies for finite population. The confidence interval was 95 percent and the standard error five percent, resulting in a sample of 232 women. To this, we added 10 percent, which amounted to 255 women, to take into account the possibility of losses. Without accounting for this eventuality, the final sample size was 240 women.

The sampling was probabilistic and separated by conglomerates, usually defined from geographical or political boundaries. This is a technique where the sample units are groups (clusters) of elements. The conglomerates must be heterogeneous, but very similar to each other in relation to the variable of interest. More than representative of population 
subsets, the clusters must contain characteristics of the total population ${ }^{(9)}$.

Data collection was conducted between April and July 2012. At this time, the city had 88 teams at FHS, totaling 528 micro areas. A community health agent ( $\mathrm{CHA}$ ) operated by micro-area, and this micro-area is considered a conglomerate in the study.

The draw of the clusters was performed using Microsoft Excel software, v2004, using the list from the CHA's that make up the family health teams, and totaling 30 micro areas. Once the CHA's for each cluster were known, seven cards " $A$ " (record of the ISPC, containing registration data of the enrolled families), corresponding to seven women aged between 20 and 59 years, were selected.

Only one woman per household was included. The homes where there was no woman in the age range required, and those homes where there were pregnant or lactating women, women in a wheelchair, bedridden or who refused to participate, were re-drawn.

A data collection instrument developed by the authors and tested through a pilot study to verify its relevance was used. The variables included in the instrument were defined based on questionnaires validated by other authors, namely: socioeconomic, based on the Giant study ${ }^{(10)}$; those related to dietary assessment, adapted from the Food Frequency Questionnaire (FFQ) ${ }^{(11)}$; and those related to physical activity, adapted from the International Physical Activity Questionnaire in a reduced version (short IPAQ)(12).

The dependent variable was the BMI, calculated by the software Statistical Package for Social Sciences (SPSS) version 17.0, by means of the formula BMI = weight $(\mathrm{kg}) /$ height $^{2}$ $\left(\mathrm{m}^{2}\right)$, and categorized as suggested by the World Health Organization (WHO) as follows: underweight $<18.5 \mathrm{~kg} \mathrm{~m}^{2}$; normal weight, be- tween 18.5 and $24.9 \mathrm{~kg} \mathrm{~m}^{2}$; overweight, from 25 to $29.9 \mathrm{~kg} \mathrm{~m}^{2}$; class I obesity, between 30.0 and $34,9 \mathrm{~kg} \mathrm{~m}^{2}$; obesity class II, from 35.0 to $39,9 \mathrm{~kg} \mathrm{~m}^{2}$; grade III or morbid obesity rates equal to or greater than $40,0 \mathrm{~kg} \mathrm{~m}^{2(13)}$. For the realization of statistical analysis, BMI was dichotomized into "low or normal BMI" (including women who were underweight and had normal weight) and "high BMI" (including women who were overweight and obese).

The continuous independent variables were age and number of children, and the dichotomous variables were age (20-40 years/41-59 years); marital status (living alone/ living with partner); religion (religion/no religion); education (low/high, considering "high schooling" having complete or incomplete high school); work (perform some sort of paid work/no work); income (high/low, considering "low" one or less than one on the minimum wage); alcohol consumption (too much drinking/little drinking); contraceptive use (yes/no); hormone replacement (yes/no); smoking (yes/no); regular physical exercise (yes/no); had a disease associated with obesity (yes/no); reuse of cooking oil (yes/no); how drinks are sweetened (sugar/ sweetener or anything); use of butter (yes/ no); consumption of soft drinks, candies, industrialized juice, breads, pastries, fried foods, and canned foods, dichotomized into "much" or "little."

To measure weight, a portable digital scale calibrated to $150 \mathrm{~kg}$ with $100 \mathrm{~g}$ precision was used. Height was measured with a portable stadiometer, which allowed the precise recording of tenths of inches. Basic care, such as the removal of shoes and the use of light clothing were indicated to the respondents during the measurements, and these details were collected after the interview.

Data was stored and analyzed using SPSS 
software, and was available for testing for 15 days. We calculated measures of central tendency and dispersion (averages, standard deviations and ranges), as well as simple and relative frequencies.

We then tested the nature of the distribution of the continuous variables (BMI, age and number of children) in order to verify the normality of the data by means of the Komolgorov-Smirnoff test and the homogeneity of variances using the Levene test. The number of children variable did not present a normal distribution. Age and BMI were crossed by means of Pearson's P test.

The categorical variables were compared with BMI using the Chi-square test, and presented the odds ratio and a respective confidence interval of 95 percent. The variables that presented association equal to or less than 0.02 were entered into a logistic regression model adjusted by the Backward model. We used the value $p<0.05$ for the consideration of the statistical significance of hypothesis tests. The research project was approved by the Research Ethics Committee of the Federal University of Juiz de Fora, according to Opinion No. 293/2010.

\section{RESULTS}

In the women studied, the prevalence of obesity was 37.08 percent ( $n=89$-Table 1$)$. The average weight of the women was $71,43 \mathrm{~kg} \pm$ 15.50; the maximum weight was $131 \mathrm{~kg}$ and the minimum was $36 \mathrm{~kg}$. The average height of the women was $1.58 \mathrm{~m} \pm 0.07$ (minimum $=1.40 \mathrm{~m}$; maximum $=1.75 \mathrm{~m}$ ). In relation to $\mathrm{BMI}$, the average was $28,58 \mathrm{~kg} / \mathrm{m} 2 \pm 5.78$, the maximum was $53,01 \mathrm{~kg} / \mathrm{m} 2$ and the minimum was 15.01.
Table 1 - Distribution of women according to BMI, Juiz de Fora (MG), 2012

\begin{tabular}{lcc}
\hline \multicolumn{1}{c}{ Variables } & $\mathbf{n}$ & $\%$ \\
\hline Low weight & 4 & 01,70 \\
Normal weight & 81 & 33,80 \\
Excess weight & 66 & 27,50 \\
Class I obesity & 55 & 22,84 \\
Class II obesity & 23 & 09,49 \\
Class III obesity & 11 & 04,75 \\
Total & 240 & 100,00 \\
\hline
\end{tabular}

Source: Data collected in this research.

The average age of the women was 40.85 years, and the standard deviation was 11.22 (the youngest was 20 and the oldest was 59 years old). As for the number of children, the participants had on average $1.99 \pm 1.45$, in which case the minimum number was zero and the maximum was 13 children per woman. BMI was positively correlated with the age variable ( $p=0.000$, Pearson's $P=0.25$ ). There was no correlation with the number of children.

With respect to socioeconomic factors, most women surveyed claimed to be aged between 41 and 59 years (55.4 percent, $\mathrm{n}=133$ ), not to be single (94.2 percent, $\mathrm{n}=226$ ), had a religion (96 percent $n=232$ ), had high education (90.4 percent, $\mathrm{n}=217$ ), did not work (52.1 percent, $n=125$ ) and had low income (65 percent, $n=156)$.

Regarding lifestyle, most women admitted to regularly consuming some type of alcoholic beverage (91.3 percent, $n=219$ ), not using contraceptives (76.7 percent, $n=184$ ), not using hormone replacements (97.9percent, $\mathrm{n}=235$ ), not smoking (75.8 percent, $\mathrm{n}=182$ ) and not regularly performing any type of physical activity (85.8 percent, $n=206$ ). Most women experienced some obesity-associated diseases, such as hypertension, diabetes mellitus and changes in the thyroid (52.5 percent, $\mathrm{n}=126$ ). 
Most women consumed large quantities of soft drinks (70.8 percent, $n=170$ ), industrialized juices (64.2 percent, $n=154)$, breads and cakes (90 percent, $n=216$ ), fried foods (70.8 percent, $n=170$ ), embedded foods (54 percent, $n=129$ ) and canned foods (51.3 percent, $\mathrm{n}=123)$; reused oil for preparing meals several times (73.3 percent, $n=176)$, used butter or oil, products rich in saturated fat (72.9 percent, $\mathrm{n}=175)$ and sugar to sweeten beverages (87.9 percent $\mathrm{n}=211$ ).

$\mathrm{BMI}$ is associated with the following variables: age $(p=0.000, O R=3.35, C l=1.9$ to 5.8$)$, contraceptive use $(p=0.00)$, some diseases associated with obesity $(p=0,00)$ and the use of sugar to sweeten drinks $(p=0.00, O R=3.8$, $\mathrm{Cl}=11.5$ ) (Table 2).

Table 2 - Table 2 X 2 linking BMI and the socioeconomic variables. Juiz de Fora, 2012.

\begin{tabular}{|c|c|c|c|c|c|c|c|c|c|c|}
\hline & \multirow{2}{*}{ BMI } & \multicolumn{2}{|c|}{ Low } & \multicolumn{2}{|c|}{ High } & \multicolumn{2}{|c|}{ Total } & \multirow{2}{*}{$p^{*}$} & \multirow{2}{*}{$\mathrm{OR}^{* *}$} & \multirow{2}{*}[IC]{$^{* * *}$} \\
\hline & & $\mathbf{n}$ & $\%$ & $\mathbf{n}$ & $\%$ & $\mathbf{n}$ & $\%$ & & & \\
\hline \multirow{3}{*}{ Elitism } & Little & 7 & 2,9 & 14 & 5,8 & 21 & 8,8 & & & \\
\hline & Much & 78 & 32,5 & 141 & 58,8 & 219 & 91,3 & & & \\
\hline & Total & 85 & 35,4 & 155 & 64,6 & 240 & 100,0 & 0,83 & 0,9 & {$[0,3-2,3]$} \\
\hline \multirow[t]{3}{*}{ Contraceptive } & Yes & 29 & 12,1 & 27 & 11,3 & 56 & 23,3 & & & \\
\hline & No & 56 & 23,3 & 128 & 53,3 & 184 & 76,7 & & & \\
\hline & Total & 85 & 35,4 & 155 & 64,6 & 240 & 100,0 & 0,00 & 2,4 & {$[1,3-4,5]$} \\
\hline \multirow[t]{3}{*}{ Replenishment Hormonal } & Yes & 0 & 0,0 & 5 & 2,1 & 5 & 2,1 & & & \\
\hline & No & 85 & 35,4 & 150 & 62,5 & 235 & 97,9 & & & \\
\hline & Total & 85 & 35,4 & 155 & 64,6 & 240 & 100,0 & 0,09 & - & - \\
\hline \multirow[t]{3}{*}{ Smoker } & Yes & 23 & 9,6 & 35 & 14,6 & 58 & 24,2 & & & \\
\hline & No & 62 & 25,8 & 120 & 50,0 & 182 & 75,8 & & & \\
\hline & Total & 85 & 35,4 & 155 & 64,6 & 240 & 100,0 & 0,43 & 1,2 & {$[0,6-2,3]$} \\
\hline \multirow[t]{3}{*}{ Regular physical Activities } & Yes & 13 & 5,4 & 21 & 8,8 & 34 & 14,2 & & & \\
\hline & No & 72 & 30,0 & 134 & 55,8 & 206 & 85,8 & & & \\
\hline & Total & 85 & 35,4 & 155 & 64,6 & 240 & 100,0 & 0,71 & 1,1 & {$[0,5-2,4]$} \\
\hline \multirow[t]{3}{*}{ Associated Diseases } & Yes & 27 & 11,3 & 87 & 36,3 & 114 & 47,5 & & & \\
\hline & No & 58 & 24,2 & 68 & 28,3 & 126 & 52,5 & & & \\
\hline & Total & 85 & 35,4 & 155 & 64,6 & 240 & 100,0 & 0,00 & 0,2 & {$[0,2-0,6]$} \\
\hline \multirow[t]{3}{*}{ Use the oil Several times? } & Yes & 62 & 25,8 & 114 & 47,5 & 176 & 73,3 & & & \\
\hline & No & 23 & 9,6 & 41 & 17,1 & 64 & 26,7 & & & \\
\hline & Total & 85 & 35,4 & 155 & 64,6 & 240 & 100,0 & 0,91 & 0,9 & {$[0,5-1,7]$} \\
\hline \multirow[t]{3}{*}{ Sweeten drinks } & Sugar & 81 & 33,8 & 130 & 54,2 & 211 & 87,9 & & & \\
\hline & Others & 4 & 1,7 & 25 & 10,4 & 29 & 12,1 & & & \\
\hline & Total & 85 & 35,4 & 155 & 64,6 & 240 & 100,0 & 0,00 & 3,8 & {$[1,3-11,5]$} \\
\hline \multirow[t]{3}{*}{ Butter } & Good & 29 & 12,1 & 36 & 15,0 & 65 & 27,1 & & & \\
\hline & Bad & 56 & 23,3 & 119 & 49,6 & 175 & 72,9 & & & \\
\hline & Total & 85 & 35,4 & 155 & 64,6 & 240 & 100,0 & 0,06 & 1,7 & {$[0,9-3,0]$} \\
\hline \multirow[t]{3}{*}{ Softdrinks } & Little & 24 & 10,0 & 46 & 19,2 & 70 & 29,2 & & & \\
\hline & Much & 61 & 25,4 & 109 & 45,4 & 170 & 70,8 & & & \\
\hline & Total & 85 & 35,4 & 155 & 64,6 & 240 & 100,0 & 0,81 & 0,9 & {$[0,5-1,6]$} \\
\hline \multirow[t]{3}{*}{ Candies } & Little & 57 & 23,8 & 111 & 46,3 & 168 & 70,0 & & & \\
\hline & Much & 28 & 11,7 & 44 & 18,3 & 72 & 30,0 & & & \\
\hline & Total & 85 & 35,4 & 155 & 64,6 & 240 & 100,0 & 0,46 & 0,8 & {$[0,4-1,4]$} \\
\hline \multirow[t]{3}{*}{ Industrialized juice } & Little & 37 & 15,4 & 49 & 20,4 & 86 & 35,8 & & & \\
\hline & Much & 48 & 20,0 & 106 & 44,2 & 154 & 64,2 & & & \\
\hline & Total & 85 & 35,4 & 155 & 64,6 & 240 & 100,0 & 0,06 & 1,6 & {$[0,9-2,8]$} \\
\hline
\end{tabular}




\begin{tabular}{llccccccccc}
\hline Bread / cake & Little & 6 & 2,5 & 18 & 7,5 & 24 & 10,0 & & \\
& Much & 79 & 32,9 & 137 & 57,1 & 216 & 90,0 & & \\
& Total & 85 & 35,4 & 155 & 64,6 & 240 & 100,0 & 0,26 & 1,3 & {$[0,7-2,2]$} \\
\hline Frying & Little & 25 & 10,4 & 45 & 18,8 & 70 & 29,2 & & \\
& Much & 60 & 25,0 & 110 & 45,8 & 170 & 70,8 & & \\
& Total & 85 & 35,4 & 155 & 64,6 & 240 & 100,0 & 0,95 & 0,6 & {$[0,3-1,1]$} \\
\hline Sausages & Little & 35 & 14,6 & 75 & 31,4 & 110 & 46,0 & & \\
& Much & 50 & 20,9 & 79 & 33,1 & 129 & 54,0 & & \\
& Total & 85 & 35,6 & 154 & 64,4 & 239 & 100,0 & 0,26 & 2,1 & {$[0,8-5,8]$} \\
\hline Canned food & Little & 42 & 17,5 & 75 & 31,3 & 117 & 48,8 & & & \\
& Much & 43 & 17,9 & 80 & 33,3 & 123 & 51,3 & & & \\
& Total & 85 & 35,4 & 155 & 64,6 & 240 & 100,0 & 0,87 & 1,2 & {$[0,6-2,1]$} \\
\hline Source:Data collected in this research & & & & & & & &
\end{tabular}

Source: Data collected in this research.

${ }^{*}$ Result of the significance of the chi-square test.

** Odds Ratio

*** Confidence Interval

The variables (age, diseases associated with obesity, contraceptive use and how drinks are sweetened) that were associated $(p<0.02)$ to the BMI variable were entered in a model of adjusted logistic regression using the Backward model. The association of the variables "age" and "how drinks are sweetened" with BMI was confirmed, as shown in Table 3.

Table 3 - Results of the logistic regression adjusted by the Backward model, Juiz de Fora (MG), 2012

\begin{tabular}{lccccc}
\hline & OR $^{*}$ & $\mathbf{I C}^{* *}$ & $\mathbf{p}^{* * *}$ & $\mathbf{R 2} \mathbf{2}^{* * *}$ & $\mathbf{C}^{* * * *}$ \\
\hline Age & 3,17 & {$[1,8-5,5]$} & 0,00 & & \\
$\begin{array}{l}\text { swee- } \\
\text { tening } \\
\text { drinks }\end{array}$ & 3,32 & {$[1,2-11,7]$} & 0,03 & 0,134 & 0,67 \\
\hline
\end{tabular}

Source: Data collected in this research.

* Odds Ratio

** Confidence interval

*** Test significance

**** Regression Results

***** Test accuracy

These variables have an association directly proportional to BMI, possibly inferring that the addition of a unit of age increases the chance of a woman being obese or overweight by 3.17 times. Furthermore, the addition of a unit because the women use sugar to sweeten beverages increases the chance of them being obese or overweight by 3.32 times.

\section{DISCUSSION}

The results indicate that the prevalence of obesity in this sample of women (37.08 percent) was higher than the worldwide (14 percent $)^{(3)}$ and national (16.9 percent\%) prevalence ${ }^{(4)}$. The findings are close to those observed in other world cities, such as in Gaziantep, Turkey (33.7 percent) ${ }^{(5)}$ and West Virginia (25 percent) $)^{(14)}$, as well as in some Brazilian cities, such as Criciúma (SC - 34.1 percent) $)^{(15)}$ and Santarém (PA - 32.8 percent) ${ }^{(16)}$.

No association between $\mathrm{BMI}$ and the marital status of the investigated women was identified in this study, which may be related to the fact that almost all participants lived with a partner (94.2 percent; $\mathrm{n}=226$ ). In a similar study conducted in Brazil, women who had stable relationships had a greater chance of being overweight compared to those women without a partner ${ }^{(4)}$. The same result was found in the study carried out in Santarém ${ }^{(16)}$.

The socioeconomic characteristics of the study sample are similar to those in an analysis carried out in São Paulo of 298 women aged 
between 20 and 59 years, who were users of a Unit of the Family Health Strategy, and where the majority had incomes lower than two minimum wages (52 percent) and lived with a partner (71 percent) ${ }^{(17)}$. A study conducted in the Republic of Mauritius showed that low socioeconomic status was a risk factor for obesity among the surveyed women ${ }^{(18)}$.

In developed countries, obesity tends to be more prevalent among those with low incomes than those with high incomes. It is probable that among the various factors that contribute to this is the low cost of high-calorie foods such as fried or processed foods when compared with fruits and vegetables ${ }^{(3)}$.

The participants had an educational level considered high (90.5 percent, $\mathrm{n}=217$ ), which meant it was not possible to relate obesity to education levels. However, a Brazilian investigation showed the highest prevalence of overweight women was observed among women with lower levels of education ${ }^{(4)}$.

The average age of the sample participants was $40.85 \pm 11.22$ years, which was similar to those in a survey conducted in Criciúma, Santa Catarina between 2006 and 2007 (42 \pm 12 years) (15).

The results of this study show a strong association between BMI and age, as was seen in an analysis carried out in Gaziantep, Turkey ${ }^{(5)}$. The investigation of obesity conducted in Brazil showed that being overweight and obesity was more likely among older women (55 years or older) $)^{(4)}$. A survey conducted in Santarém also concluded that excess weight increases with age, affecting 58.3 percent of the population aged over $55^{(16)}$.

Hormonal fluctuations in women may explain the increased risk of obesity. Changes during the menstrual cycle affect the intake of calories and nutrients, and cause changes in energy expenditure ${ }^{(19)}$. Menopause, characteri- zed by the end of female reproductive function, is presented as a factor that can contribute to weight gain. The aforementioned study in the Republic of Mauritius evidenced that being postmenopausal constituted a risk factor for obesity, compared to women in the pre-menopause period $^{(18)}$.

The data from this study shows a strong correlation ( $p=0.00, O R=2.5, C l=1.3-4.5$ ) between $\mathrm{BMI}$ and contraceptive use, but no association was observed between BMI and the use of hormone replacements. These findings differ from the results found in the research carried out in Criciúma, which shows no association between the use of contraceptive methods/hormone replacement therapy and women being overweight/obese ${ }^{(15)}$.

In this study, we observed a positive association $(p=0.00)$ between BMI and obesity-related diseases. This was corroborated by a Brazilian survey which showed that the prevalence of hypertension, diabetes mellitus, myocardial infarction, stroke, dyslipidemia and osteoporosis was higher among individuals with higher $\mathrm{BMI}^{(4)}$.

With respect to the use of tobacco, the sample results did not identify an association between BMI and smoking ( $p=0.43)$. However, a cross-sectional study, aimed at investigating the association between excess weight and smoking, found that the prevalence of being overweight was higher for women smokers compared to former smokers and those who never smoked ${ }^{(16)}$.

An association between sugar consumption and BMI was observed. A similar result was found in a survey conducted in the United Kingdom (UK), which showed that sugar consumption was one of the significant predictors of obesity. The association between sweets and obesity suggests that effective strategies should be designed and implemented in order to reduce its consumption in the population ${ }^{(20)}$. 
It is noted that worldwide, there is an association between urbanization and the increased consumption of high-calorie foods with high levels of fat, sugar and salt ${ }^{(3)}$.

This study aims to present the prevalence of obesity in adult women in a city in the Zona da Mata region in Minas Gerais State. Considering global socioeconomic and cultural diversity, it is not possible to generalize the results to other Brazilian and/or international contexts.

\section{CONCLUSION}

The findings of this investigation indicate that the high prevalence of female obesity appears to be an important public health problem in the municipality studied.

Considering that the sample represents the population of adult women enrolled in the family health strategy, it is up to the nurse, who is an important social actor in this context, to provide support to these patients, acting on obesity and the factors that are associated with it, as identified in this study.

In order to gain control of the disease, it is suggested that the municipal authorities use the results of this research to develop health policies in primary health care that meet the care needs of those with chronic conditions, which is a challenge for the professionals who work within the context of the UHS.

It is recommended that similar studies be conducted in other areas of Brazil, in order to identify whether the high prevalence of female obesity is a specific reality or is present in other municipalities. Moreover, considering the disparity in obesity prevalence between the study sample and that found at national and international levels, we propose the development of longitudinal research that is capable of suggesting causal relations in order to explain these results.

\section{REFERENCES}

1. Costa, ACC, Ivo ML, Cantero WB, Tognini JRF. Obesity in candidates for bariatric surgery Acta Paul Enferm. 2009; 22(1): 55-9.

2. Santos A, Pasquali R, Marcon S. Feelings and experiences of obese participants, in a support group: an exploratory study. Online Braz J Nurs (Online) [Internet]. 2012 Apr 18; [Cited 2013 May 10] 11(1). Available from: http://www.objnursing.uff.br/index.php/ nursing/article/view/3251. doi http://dx.doi. org/10.5935/1676-4285.20120002

3. World Health Organization. World Health Statistics 2012 [homepage]. [cited $2013 \mathrm{fev}$ 27] Available from: http://www.who.int/gho/publications/world_health_statistics/2012/en/

4. Ministério da Saúde (Brasil) [homepage]. Secretaria de Vigilância em Saúde. Vigilância de Fatores de Risco e Proteção para Doenças Crônicas por meio de Inquérito Telefônico. VIGITEL. [cited 2014 aug 28]. Available from: http://bvsms.saude.gov.br/bvs/publicacoes/ vigitel_brasil_2012_vigilancia_risco.pdf

5. Ozcirpici B, Coskun F, Sahınoz S, Ozgur S, Bozkurt Al. Obesity Prevalence in Gaziantep, Turkey. Indian J Community Med. 2009; 34(1): 29-34. doi: 10.4103/0970-0218.45371

6. DATASUS [Internet]. Estado Nutricional: Usuários da Atenção Básica de Minas Gerais acompanhados por faixas de idade segundo sexo; 2007 [cited 2014 aug 28]. Available from: http://tabnet.datasus.gov.br/cgi/tabcgi. exe?sisvan/cnv/acom_mg.def

7. Instituto Brasileiro de Geociências e Estatísticas (Brasil). [homepage]. Minas Gerais. Cidades. População 2010. [citedited 2013 may 26]. Available from: http://www.ibge.gov.br/ cidadesat/link.php?uf=mg.

8. Secretaria de Estado da Saúde de Minas Gerais. Gerência Regional de Saúde de Juiz de Fora. Sistema de Informação em Saúde (SIAB) [homepage]. [cited 2013 may 26]. Available from:http://www.saude.mg.gov.br/institucional/integracao-institucional/grs/GRS.

9. Pezzoli L, Pineda S, Halkyer P, Crespo G, Andrews N, Ronveaux O. Cluster-sample surveys 
and lot quality assurance sampling to evaluate yellow fever immunisation coverage following a national campaign, Bolivia, 2007. Trop Med Int Health. 2009; 14(3): 355-61. doi: 10.1111/j.1365-3156.2009.02231

10. Gigante DP, Moura E C, Sardinha LMV. Prevalence of overweight and obesity and associated factors, Brazil, 2006. Rev Saúde Pública. 2009; 43(supl.2): 83-9. http://dx.doi.org/10.1590/ S0034-89102009000900011

11. Molina BMC, Benseñor IM, Cardoso LO, Velasquez-Melendez G, Drehmer M, Pereira TSS et al. Reproducibility and relative validity of the Food Frequency Questionnaire used in the ELSA-Brasil. Cad Saúde Pública. 2013; 29(2): 379-89. http://dx.doi.org/10.1590/S0102$-311 \times 2013000200024$

12. Lee PH, Macfarlane DJ, Lam TH, Stewart SM. Validity of the International Physical Activity Questionnaire Short Form (IPAQ-SF): a systematic review. Int J Behav Nutr Phys Act. 2011; 8: 115. doi:10.1186/1479-5868-8-115

13. World Health Organization [homepage on the internet]. BMI Classification. Cited 2013 mar 10. Available from: http://www.who.int/bmi/ index.jsp?introPage=intro_3.html.

14. Amarasinghe A, D'Souza G, Brown C, Oh $H$, Borisova T. The influence of socioeconomic and environmental determinants on health and obesity: a West Virginia case study. Int J Environ Res Public Health. 2009; 6(8): 227187. doi:10.3390/ijerph6082271

15. Rosa MI, Silva FML, Giroldi SB, Antunes GN, Wendland EM. The prevalence and factors associated with obesity in women attended at First Aid Units of the Unified Health System in southern Brazil. Cien Saude Colet. 2011; 16(5): 2559-66. http://dx.doi.org/10.1590/S141381232011000500026

16. Sá NNB, Moura EC. Association between overweight and smoking habits, Santarém, PA, 2007. Rev Bras Epidemiol. 2009; 12(4): 636-45. http://dx.doi.org/10.1590/S1415-790X2009000400013

17. Cristóvão MF, Sato APS, Fujimori E. Overweight and abdominal obseity in women users of a family health strategy unit. Rev Esc Enferm USP. 2011; 45(spe2): 1667-72. http://dx.doi.
org/10.1590/S0080-62342011000800005

18. Bhurosy $t$, Jeewon R . Food habits, socioeconomic status and body mass index among premenopausal and post-menopausal women in Mauritius. J Hum Diet Nutr. 2013; 26 (Suppl. 1): 114-22. doi:10.1111/jhn.12100

19. Moilanen J, Aalto AM, Hemminki E, Aro AR, Raitanen J, Luoto R. Prevalence of menopause symptoms and their association with lifestyle among Finnish middle-aged women. Maturitas. 2010; 4(67): 368-74. doi: 10.1016/j. maturitas.2010.08.007

20. Siervo M, Montagnese C, Mathers JC, Soroka KR, Stephan BC, Wells JC. Sugar consumption and global prevalence of obesity and hypertension: an ecological analysis. Public Health Nutr. 2014 Mar; 17(3): 587-96. doi: 10.1017/ S1368980013000141

All authors participated in the phases of this publication in one or more of the following steps, in According to the recommendations of the International Committee of Medical Journal Editors (ICMJE, 2013): (a) substantial involvement in the planning or preparation of the manuscript or in the collection, analysis or interpretation of data; (b) preparation of the manuscript or conducting critical revision of intellectual content; (c) approval of the versión submitted of this manuscript. All authors declare for the appropriate purposes that the responsibilities related to all aspects of the manuscript submitted to OBJN are yours. They ensure that issues related to the accuracy or integrity of any part of the article were properly investigated and resolved. Therefore, they exempt the OBJN of any participation whatsoever in any imbroglios concerning the content under consideration. All authors declare that they have no conflict of interest of financial or personal nature concerning this manuscript which may influence the writing and/or interpretation of the findings. This statement has been digitally signed by all authors as recommended by the ICMJE, whose model is available in http://www.objnursing.uff.br/normas/DUDE_eng_1306-2013.pdf

Received: 06/07/2013
Revised: 08/16/2014
Approved: 09/03/2014 